\title{
COOPERATIVISMO FINANCEIRO: ANÁLISE DE DUAS MODALIDADES DE FINANCIAMENTO PARA PEQUENOS EMPREENDEDORES
}

\author{
Gustavo Passos Fortes ${ }^{1}$ \\ Maria Elena Leon Olave ${ }^{2}$ \\ Diná Vieira De Matos ${ }^{2}$ \\ Moisés Araujo Almeida ${ }^{3}$ \\ ${ }^{1}$ Universidade Federal do Sul e Sudeste do Pará \\ ${ }^{2}$ Universidade Federal de Sergipe \\ ${ }^{3}$ Universidade Federal da Paraíba
}




\section{COOPERATIVISMO FINANCEIRO: ANÁLISE DE DUAS MODALIDADES DE FINANCIAMENTO PARA PEQUENOS EMPREENDEDORES}

Resumo: O cooperativismo financeiro consiste em uma oportunidade de acesso e aplicação de recursos de forma rápida, menos burocrática e a um custo menor. Assim, também possibilita o estreitamento de laços de cooperação com outros empreendedores, desenvolvendo seu negócio de forma cooperativa. $\mathrm{O}$ microcrédito cooperativo pode ser então uma saída para o desenvolvimento das MPEs, em particular os Microempreendedores Individuais e os empreendedores informais. Nesse sentido, o presente estudo analisou duas modalidades de cooperativismo financeiro (o aval solidário e as cooperativas de crédito), buscando entender a dinâmica da cooperação da rede formada. A metodologia utilizada foi o estudo de casos múltiplos com a aplicação de entrevistas semiestruturadas com gestores de microcrédito cooperativo e empreendedores. Os resultados sugerem uma grande satisfação e desenvolvimento das MPEs, assim como evidencia desafios e oportunidades para a dinâmica de redes de cooperação no setor de microcrédito em ambas modalidades.

Palavras-chave: Aval solidário. Cooperativismo financeiro. Cooperativas de crédito. Microcrédito. 


\section{Introdução}

Em 2005, o governo brasileiro promulgou a lei 11.110/05 e o Programa Nacional de Microcrédito Produtivo Orientado - PNMPO que regulariza e incentiva fomentar crédito para microempresas, microempreendedores populares, formais e informais. O PNMPO consiste na concessão de empréstimo de pequeno valor e determina, em lei, prazos, limites e taxas de juros diferenciados (MAGDALON; FUNCHAL, 2016).

A falta de alternativas satisfatórias de ocupação e renda são os principais desencadeadores do empreendedorismo de pequeno porte, gerando o autoemprego (ANTHONY, 2005). Assim, tal como afirma Magdalon e Funchal (2014) o microcrédito surge nesse contexto como uma alternativa de concessão de crédito à população de baixa renda que tem dificuldades de acesso aos serviços financeiros tradicionais. Tal modalidade reforça o cooperativismo financeiro como uma alternativa de correta aplicação e desenvolvimento dos empreendedores pela utilização do microcrédito orientado (KHAVUL; CHAVEZ; BRUTON, 2013).

Varias são as modalidades desse cooperativismo financeiro que se aplicam ao microcrédito, no contexto das micro finanças (ORDANINI et al., 2011 ; ANTHONY, 2005). Nesse sentido, o cooperativismo financeiro no microcrédito, muito além de conceder o crédito, auxilia no desenvolvimento dos empreendedores reduzindo a mortalidade empresarial favorecendo a interação em redes de cooperação (ORDANINI et al., 2011 ; SANTOS, 2009).

O presente artigo pretende analisar a utilização do microcrédito cooperativo em duas modalidades de cooperativismo financeiro distintas. A primeira refere-se ao chamado aval solidário, que tem como objetivo a atuação e comprometimento de grupos de empreendedores na obtenção, aplicação e pagamento do crédito. A segunda refere-se às cooperativas de crédito que atuam no desenvolvimento do empreendedor cooperado dentro da rede de cooperação. De forma ampla essas duas modalidades contribuem para o fortalecimento da rede de cooperação a medida que favorece os laços de confiança para realizar uma atuação conjunta, seja no acompanhamento, aval ou trocas de experiências especificas (ANTHONY, 2005).

\section{Referencial Teórico}

\subsection{Cooperativismo Financeiro: Origem, Definições e Contexto:}

De acordo com o estudo de Galerani (2003) o cooperativismo, pela ótica da teoria econômica, é a pratica de um empreendimento econômico, que é constituída por uma sociedade de membros cooperantes. O objetivo é agregar valor econômico e financeiro aos seus associados, buscando condições de sobrevivência e fortalecimento econômico através das forças agrupadas e direcionadas para um objetivo em comum (MEINEN; PORT, 2014).

Nos dias atuais tem-se observado que as novas e as pequenas empresas enfrentam restrições financeiras e tem dificuldade para obter financiamentos, tais como nos bancos (KHAVUL; CHAVEZ; BRUTON, 2013). O financiamento é uma temática crítica para o
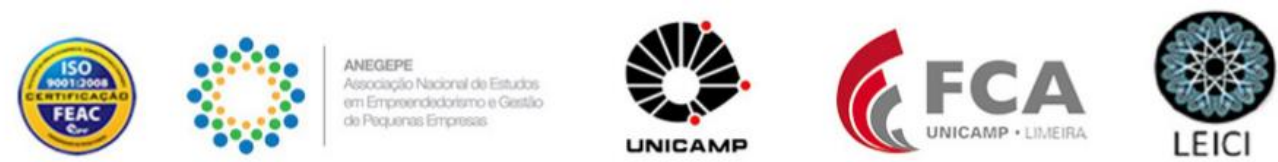
desenvolvimento do empreendedor e sua empresa (SHANE, 2000), portanto, cada vez mais pesquisas são conduzidas no sentido de analisar seu financiamento, não somente sobre o acesso do financiamento em si, mas também na aquisição de informações que melhoram a obtenção e a gestão desses recursos (KHAVUL; CHAVEZ; BRUTON, 2013). Nesse mesmo sentido, Santos (2009) demonstra que as redes de cooperação podem então auxiliar aos empreendedores na obtenção de crédito com condições de taxas, prazos e garantias adequadas às suas necessidades. Assim, partindo dessa necessidade e do conceito de cooperativismo, surgiram as primeiras cooperativas de crédito (SANTOS, 2009, MATIAS et al., 2014).

As cooperativas de crédito surgem como uma alternativa de acesso a crédito e serviços financeiros de forma cooperativa e segundo Geriz (2004), em 1848 foi fundada a primeira cooperativa de crédito na Alemanha para satisfazer às necessidades de crédito rural. Tais cooperativas de crédito seguiam o exemplo da primeira cooperativa, que se estabeleceu como alternativa ao desemprego e à crise econômica decorrentes da Revolução Industrial, a Sociedade dos Probos Pioneiros de Rochdale (GERIZ, 2004). Tal cooperativa estabeleceu os princípios cooperativistas que são tidos como base do cooperativismo autêntico até os dias de hoje, inclusive aplicados à realidade das cooperativas de crédito (GERIZ, 2004; SANTOS, 2009, MATIAS et al., 2014).

Wheelock e Wilson (2013) conceituam cooperativa de crédito como uma instituição financeira que provê depósitos, empréstimos e outros serviços a membros cooperados à instituição. As cooperativas de crédito formam, juntamente com os bancos, o sistema bancário, mas diferem-se das outras instituições financeiras devido a sua forma jurídica, visto que estas são consideradas organizações do terceiro setor (MEINEN; PORT, 2014). Tais diferenças são bastante importantes para a caracterização da rede de cooperação formada na cooperativa de crédito, visto que os objetivos da cooperativa são basicamente o desenvolvimento da cooperação e de seus membros associados (MEINEN; PORT, 2014; MATIAS et al., 2014).

As cooperativas de crédito são apenas uma das modalidades de cooperativismo financeiro possível em nossa realidade (ANTHONY, 2005; CHOLAKOVA; CLARYSSE, 2014). Modalidades como o investimento anjo, crédito de aval solidário e financiamentos coletivos baseados em recompensa ou ação tal como o crowdfunding são exemplos de modalidades bastante conhecidas (ORDANINI et al., 2011 ; CHOLAKOVA; CLARYSSE, 2014). Em tais modalidades, não necessariamente, está prevista a interação em rede dos participantes, mas indiretamente para as relações informais de cooperação (WHEELOCK; WILSON, 2013; CHOLAKOVA; CLARYSSE, 2014; ALLISON et al. 2014) .

Em 1976 Muhammad Yunus inaugurou a modalidade de crédito de aval solidário com o Grameen Bank em Bangladesh, no qual concedia-se o crédito para mulheres rurais que não tinham garantias financeiras, formando pequenos grupos de financiados da mesma comunidade servindo como uma fonte coletiva de garantias, compensando a falta de garantia

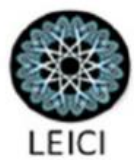


financeira dos indivíduos (RIGHETTI, 2008). No aval solidário, a instituição responsável fornece o capital de empréstimo, enquanto os membros do grupo fornecem o rastreio e supervisão dos mutuários, sendo que cada um é o avalista do outro (RIGHETTI, 2008). Funciona como um círculo informal de empréstimo conhecido como poupança rotativa e associações de crédito (RIGHETTI, 2008). Essa modalidade favorece os relacionamentos de cooperação baseada em confiança e dependência sobre as relações pessoais entre os membros do grupo. (YUNUS 2000).

No Brasil a modalidade de crédito de aval solidário ganhou visibilidade com o Programa de Microcrédito Produtivo Orientado do Banco do Nordeste, o Crediamigo, que se destaca entre as iniciativas de políticas de microcrédito, além de ser considerado o maior programa de microcrédito produtivo orientado do país. Os públicos-alvo do programa são autônomos, empreendedores individuais ou reunidos em grupos solidários que atuam nos setores formal ou informal da economia (BANCO DO NORDESTE, 2016).

Uma das características do crédito de aval solidário é a formação de um grupo de três ou mais pessoas conhecidas entre si, que recebem um crédito orientado, sendo que cada um dos membros garante o pagamento dos demais integrantes do grupo (NERI, 2008). Esta forma de financiamento é uma alternativa para aqueles empreendedores, que normalmente não possuem acesso ao sistema financeiro tradicional, principalmente, por oferecer garantias reais ou devido a informalidade (NERI, 2008; SOUZA, 2010).

\subsection{O Microcrédito}

As Micro e Pequenas Empresas (MPEs) enfrentam dificuldades na obtenção do crédito e precisam de linhas de crédito mais adaptadas a sua realidade e necessidade, pois como afirma Silveira Filho (2005), o sistema de crédito tradicional está baseado em agências bancárias, que somente concedem o crédito mediante o cumprimento de normas, burocracias e procedimentos, além de exigirem garantias reaisAssim, uma importante fonte de financiamento para as MPEs é o microcrédito, pois, muitas vezes elas não podem oferecer garantias reais ou mesmo assumir uma dívida em longo prazo (BARONE et al., 2002).

Conceitualmente, "o microcrédito é a concessão de empréstimos de baixo valor a pequenos empreendedores informais e microempresas sem acesso ao sistema financeiro tradicional", muitas vezes devido à falta de informação e garantias (BARONE et al., 2002, p. 11). Da mesma forma, Barone et al. (2002) afirmam que ele é concedido com o uso de uma metodologia específica que auxilia a correta aplicação do recurso que, de acordo com Meinen e Port (2014), possibilita a geração de emprego e renda e desenvolvimento de empreendedores e microempresas com a obtenção de recursos mínimos (KHAVUL, 2010).

Silva (2007 destaca alguns tipos de microcrédito, a saber: 1) microcrédito tradicional, com a finalidade de fornecer serviço de microcrédito voltado para o consumo de famílias de baixa renda; 2) microcrédito produtivo, voltado a oferecer crédito de pequeno valor à empresas e; 3) microcrédito produtivo orientado, que se caracteriza como o crédito para os

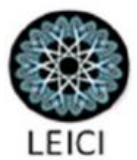


empreendedores, embasado no relacionamento entre a instituição de microcrédito e o grupo de empreendedores, através dos agentes de crédito. Este último caracteriza a particularidade do cooperativismo financeiro tanto nas cooperativas de crédito como na modalidade de aval solidário (SANTOS; GOIS, 2011; MEINEN; PORT, 2014).

De modo geral, existem três justificativas para a consolidação e crescimento do mercado de microcrédito: 1) quantidade de empreendedores informais; 2) desemprego e; 3 ) dificuldades de acesso ao crédito tradicional (MENEZES, OURO FILHO, SANTANA, 2014). Assim, de acordo com o SEBRAE (2014), as principais características desse microcrédito produtivo orientado são: garantias mais simples e mais adequadas à realidade dos pequenos empreendedores; utilização do aval solidário; garantia reais raras; a quantidade de crédito e as parcelas para pagamento de acordo com a necessidade e possibilidades do empreendedor e seu grupo; e; acompanhamento e relacionamento com agentes de crédito na aplicação dos recursos e desenvolvimento do negocio (BARONE et al., 2002).

A atuação do agente de crédito é de grande importância, pois substitui a necessidade de garantias reais e ajuda na capacitação do empreendedor (ALICE, L.; RUPPENTHAL,2012). A assistência continuada do agente de crédito possibilita um relacionamento de confiança e aproximação com outros empreendedores do grupo, pois fortalece as interações da rede, favorecendo a evolução e consolidação dos empreendimentos. "Além disso, favorecem ao tomador novas oportunidades de crédito, para o desenvolvimento ou ampliação dos negócios” (ALICE.; RUPPENTHAL, 2012, p. 28).

\subsection{Programas e instituições de microcrédito no Brasil:}

Visto a grande demanda por crédito por parte dos empreendedores e a dificuldade de acesso a linhas disponíveis, a modalidade de microcrédito evidenciou-se no Brasil um crescimento acelerado nos últimos anos (MENEZES, OURO FILHO, SANTANA, 2014). Alice e Ruppenthal (2012) lembram que devido a esse crescimento, o Programa Nacional de Microcrédito Produtivo Orientado (Lei $\mathrm{n}^{\circ}$ 11.110/05), gerou mudanças e avanços significativos no Brasil. As organizações de microcrédito, as cooperativas de crédito, agências de fomento e bancos de desenvolvimento passaram a ter oportunidade de acessar recursos do Fundo de Amparo ao Trabalhador (FAT) e da parcela dos recursos de depósitos à vista, destinada ao microcrédito (Lei $\mathrm{n}^{\circ} 10.735 / 03$ ).

Apesar de importantes iniciativas e conquistas, a indústria de microcrédito no Brasil ficou praticamente estagnada até 1994, devido à instabilidade econômica no Brasil, com as altas taxas inflacionárias, a tradição de crédito governamental dirigido e subsidiado às diferentes modalidades de crédito ao consumidor (BARONE et al. 2002; ZOUAIN e BARONE, 2007). O crescimento do microcrédito deu-se com a consolidação do plano real, com a estabilidade econômica, aliada a oportunidades de negócios na abertura de capital e com o auxilio do BNDES, possibilitando a sustentabilidade das iniciativas de concessão de microcrédito (ZOUAIN e BARONE, 2007).

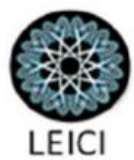


Nessa expansão, cresce o interesse dos governos municipais e estaduais na participação desse setor, incentivando e apoiando a criação de ONGs, especializadas em micro finanças (ZOUAIN e BARONE, 2007; ALICE.; RUPPENTHAL, 2012). Posteriormente no Brasil ocorre um despertar da consciência dos mais variados tipos de agências, sejam governamentais ou não, que decidiram iniciar seus próprios programas de micro finanças (ALICE.; RUPPENTHAL, 2012). A seguir o quadro 1 apresenta um comparativo das principais iniciativas que moldaram o segmento do microcrédito no Brasil:

Quadro 2 - Histórico dos Programas de microcrédito no Brasil

\begin{tabular}{|c|c|c|c|}
\hline $\begin{array}{l}\text { Programa de } \\
\text { Microcrédito }\end{array}$ & Histórico & Fonte de recursos & $\begin{array}{l}\text { Ano de } \\
\text { criação }\end{array}$ \\
\hline $\begin{array}{l}\text { O Programa } \\
\text { UNO }\end{array}$ & $\begin{array}{l}\text { Concomitantemente à concessão do crédito, capacitava os } \\
\text { clientes em temas de gestão. Produzia pesquisas sobre o } \\
\text { perfil do empresário da microempresa e o impacto do } \\
\text { crédito. }\end{array}$ & $\begin{array}{l}\text { Organização não } \\
\text { governamental, } \\
\text { sustentada por doações } \\
\text { internacionais. }\end{array}$ & 1978 \\
\hline $\begin{array}{l}\text { A Rede } \\
\text { CEAPE }\end{array}$ & $\begin{array}{l}\text { A partir da experiência da Accion International e de } \\
\text { organizações não governamentais colombianas, a } \\
\text { metodologia dos Grupos Solidários, que utiliza o aval } \\
\text { solidário, foi replicada no Brasil pelo Centro de Apoio aos } \\
\text { Pequenos Empreendimentos Ana Terra (CEAPE/RS) }\end{array}$ & $\begin{array}{l}\text { Apoio do Banco } \\
\text { interamericano de } \\
\text { Desenvolvimento/BID } \\
\text { e da Inter-American } \\
\text { foundation/IAF }\end{array}$ & 1987 \\
\hline $\begin{array}{l}\text { O Banco da } \\
\text { Mulher }\end{array}$ & $\begin{array}{l}\text { Programa de microcrédito que utiliza a metodologia de } \\
\text { Grupos Solidários. Filiado ao Women's World Banking, } \\
\text { que mantém filiados em diversos países e estados } \\
\text { brasileiros. }\end{array}$ & 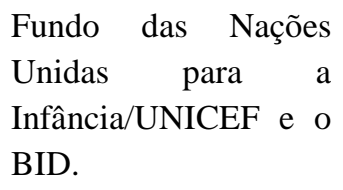 & 1989 \\
\hline A Portosol & $\begin{array}{l}\text { Prefeitura de Porto Alegre, em parceria com entidades da } \\
\text { sociedade civil. Formação de um modelo institucional que } \\
\text { vem sendo referência para a criação de várias entidades de } \\
\text { microcrédito, baseadas na iniciativa do Poder Público e } \\
\text { apoiadas no princípio da autossustentabilidade. }\end{array}$ & $\begin{array}{l}\text { Prefeitura, Governo do } \\
\text { Estado, Sociedade } \\
\text { Alemã de Cooperação } \\
\text { técnica/GTZ, Inter- } \\
\text { American } \\
\text { Foundation/IAF, } \\
\text { BNDES } \\
\text { SEBRAE/RS }\end{array}$ & 1995 \\
\hline O VivaCred & $\begin{array}{l}\text { Iniciativa do Movimento Viva Rio, com o objetivo de } \\
\text { conceder crédito aos microempreendimentos de } \\
\text { propriedade de pessoas de baixa renda das comunidades } \\
\text { carentes e favelas do Rio de Janeiro. }\end{array}$ & \begin{tabular}{l}
\multicolumn{2}{c}{ Recursos } \\
provenientes do BID, \\
BNDES e Fininvest
\end{tabular} & 1996 \\
\hline O Crediamigo & $\begin{array}{l}\text { Programa de microcrédito do Banco do Nordeste. Trabalha } \\
\text { com a metodologia de Grupos Solidários e também oferece } \\
\text { capacitação gerencial para os grupos. Constitiu-se no } \\
\text { maior programa de microcrédito do País. }\end{array}$ & $\begin{array}{l}\text { Recursos do BNB e } \\
\text { BNDS }\end{array}$ & 1998 \\
\hline
\end{tabular}

Fonte: adaptado de Barone et al. (2002). 
Por fim, um dos últimos programas a ser lançado, foi o Programa SEBRAE de Microcrédito que visa incentivar as oportunidades de acesso ao crédito para os pequenos empreendimentos, principalmente os informais. Lançado em 2001, como instituição de "segunda linha", propõe apoiar a criação e o fortalecimento de organizações de microcrédito, desde que adotem os princípios de independência e auto ssustentabilidade. Prevê apoio à reestruturação das instituições; capacitação de recursos humanos; cessão de uso de sistema informatizado de gestão; prestação de serviços de consultoria; capacitação de lideranças comunitárias; dentre outros (SEBRAE, 2014; BARONE et al. 2002, p. 18).

\section{Procedimentos metodológicos}

O presente estudo é caracterizado como qualitativo, de natureza descritiva. No estudo descritivo o pesquisador trata o assunto conduzindo a pesquisa e descrevendo cuidadosamente o fenômeno observado (NEUMAN, 1997). De qualquer forma, Saunders, Lewis e Thornill (2000) reforçam que não basta apenas descrever, é preciso realizar conclusões, avaliações dos dados e sintetizar as ideias. Foi utilizado o estudo de casos múltiplos, por investigar a situação com diversas unidades de interesse, e múltiplo por incluir mais de um caso unitário, buscando entender com a utilização de replicações teóricas e literais (YIN, 2003).

As unidades de observação são programas de microcrédito cooperativo destinado a MPEs. Os casos analisados, com a utilização da amostragem intencional, por perceber a utilização do cooperativismo financeiro na obtenção e utilização de microcrédito. A amostragem intencional na escolha dos casos pode ser identificada na definição de casos com indivíduos contatados que dispõem de tempo para conceder as entrevistas (NEUMAN, 1997). Nesse sentido o estudo verificou a modalidade de microcrédito de aval solidário disponibilizada no programa Crediamigo e a modalidade de microcrédito de uma cooperativa de crédito, a Sicred/Aracaju.

Os entrevistados foram gestores dos programas de microcrédito, que compreendem quais as características do cooperativismo financeiro e as especificidades de cada modalidade. Para complementar os dados e a analise, foram entrevistados empreendedores que utilizam o microcrédito de forma cooperativa. Foram contatados microempreendedores individuais para cada uma das modalidades (crédito de aval solidário e cooperativa de crédito). Com base nas considerações de Yin (2010) que afirma que a entrevista é uma das mais importantes fontes de informações para um estudo de caso. A técnica de coleta de dados foi um roteiro de entrevista semiestruturada, escolhido pela flexibilidade de esclarecer as questões, possibilitando a avaliação de uma linguagem não verbal dos entrevistados.

Dois roteiros de entrevista foram utilizados neste estudo. O primeiro, específico para gestores dos programas, buscou compreender as características e particularidades, verificando inclusive a percepção dos gestores sobre os benefícios e pratica da modalidade. Já o segundo roteiro, com objetivo de comparação e validação das informações obtidas, foi destinado aos empreendedores clientes das modalidades de crédito estudadas. Tais roteiros foram

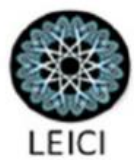


elaborados de acordo com as categorias e elementos de análise baseadas nos objetivos específicos deste estudo, e aparecem no quadro 2:

Quadro 2 - Categorias analíticas e elementos de análise

\begin{tabular}{|c|c|}
\hline Categorias Analíticas & Elementos de Análise \\
\hline $\begin{array}{l}\text { Cooperativismo financeiro na } \\
\text { SICRED e no CREDIAMIGO }\end{array}$ & $\begin{array}{l}\text { - Histórico da instituição/programa } \\
\text { - Características e funcionamento do cooperativismo nos casos; } \\
\text { - Fonte de recursos; } \\
\text { - Benefícios para o desenvolvimento das MPEs }\end{array}$ \\
\hline Modalidade de Microcrédito. & $\begin{array}{l}\text { - Vantagens e particularidades do crédito orientado para MPEs. } \\
\text { - Necessidades e garantias } \\
\text { - Público-alvo do microcrédito. }\end{array}$ \\
\hline Microcrédito cooperativo & $\begin{array}{l}\text { - Particularidade da modalidade de cooperativismo (aval } \\
\text { solidário/cooperativa de crédito) } \\
\text { - Satisfação quanto à modalidade. } \\
\text { - Desafios e oportunidade das modalidades }\end{array}$ \\
\hline
\end{tabular}

Fonte: Elaboração própria (2017)

\subsection{Coleta de dados}

Para a construção e analise do caso 1, referente à Instituição Crediamigo em Sergipe, foram entrevistados o gerente atual do Crediamigo, a gerente responsável que implantou o programa no Brasil e no estado de Sergipe, um agente de crédito ativo e um cliente atendido pelo programa, integrante de um grupo de empreendedores informais de uma comunidade de baixa renda da cidade de Aracaju/SE. Os nomes dos entrevistados não foram revelados a pedido deles, por motivos pessoais. Segue quadro 3 com a descrição do cargo e a importância para o estudo de cada um dos entrevistados.

\section{Quadro 3 - Relação de entrevistados referente ao programa Crediamigo}

\begin{tabular}{|c|c|l|l|}
\hline Entrevistados & \multicolumn{1}{|c|}{ Cargo } & \multicolumn{1}{|c|}{ Importância para o estudo } \\
\hline E1 & $\begin{array}{c}\text { Gerente atual do } \\
\text { Crediamigo }\end{array}$ & $\begin{array}{l}\text { Histórico e contexto atual sobre o } \\
\text { funcionamento do programa em SE }\end{array}$ \\
\hline E2 & $\begin{array}{l}\text { Gerente do setor de } \\
\text { retaguarda do BNB }\end{array}$ & $\begin{array}{l}\text { Primeira gerente do Crediamigo Sergipe, } \\
\text { responsável pela implantação do programa e } \\
\text { projeto piloto. }\end{array}$ \\
\hline E3 & $\begin{array}{c}\text { Agente de crédito do } \\
\text { Crediamigo }\end{array}$ & $\begin{array}{l}\text { Funcionamento da rede de cooperação e pratica } \\
\text { do programa. }\end{array}$ \\
\hline E4 & Empreendedor & $\begin{array}{l}\text { Satisfação quanto às características do } \\
\text { programa. }\end{array}$ \\
\hline
\end{tabular}

Fonte: Elaboração própria (2017). 
Já para a construção e analise do caso 2, referente à instituição SICRED, foram entrevistados um gerente de negócios, o gerente de relacionamento e um empreendedor cooperado utilitário de linhas de microcrédito promovidas pela SICRED. Da mesma forma, os nomes dos entrevistados foram preservados visando manter o padrão entre os casos. Segue quadro 4:

\section{Quadro 4 - Relação de entrevistados referente à SICRED}

\begin{tabular}{|c|c|lr|}
\hline Entrevistados & Cargo & \multicolumn{3}{|c|}{ Importância para o estudo } \\
\hline E5 & Gerente de negócios & $\begin{array}{l}\text { Histórico e contexto atual sobre o } \\
\text { funcionamento da cooperativa em SE }\end{array}$ & o dos \\
\hline E6 & $\begin{array}{l}\text { Gerente de } \\
\text { relacionamento }\end{array}$ & $\begin{array}{l}\text { Contexto do atendimento empresarial } \\
\text { cooperados, produtos e serviços. }\end{array}$ & do \\
\hline E7 & $\begin{array}{c}\text { Empreendedor } \\
\text { Cooperado }\end{array}$ & $\begin{array}{l}\text { Satisfação quanto às características } \\
\text { programa. }\end{array}$ & \\
\hline
\end{tabular}

Fonte: Elaboração própria (2017).

\section{Análise e Discussão dos casos}

\subsection{O Crediamigo}

Como proposto no estudo foi escolhido o caso do Crediamigo em Sergipe para analise e discussão do cooperativismo financeiro. A justificava da escolha foi devido à prática do grupo de aval solidário na concessão do microcrédito e funcionamento do programa de forma cooperativa. Outra justificativa importante para a escolha do caso é a rede de relacionamento formada pelos empreendedores do grupo formado e com o agente de crédito no funcionamento pleno do programa. Essas características, aliada a rede formada pelos empreendedores na aprovação e utilização do microcrédito permitiu considerar o aval solidário praticado no Crediamigo uma importante modalidade de cooperativismo financeiro.

O Crediamigo, considerado o maior programa de microcrédito do Brasil, é um programa de Microcrédito Produtivo Orientado do Banco do Nordeste que tem por objetivo oferecer crédito às pessoas que trabalham por conta própria, empreendedores individuais reunidos em grupos solidários que atuam nos setores formal ou informal da economia. Iniciou-se com um projeto piloto em 1997, passando efetivamente a operar em 1998 com a abertura de 45 unidades, e atualmente está presente em mais de 2 mil municípios do Nordeste, norte de Minas Gerais e Espírito Santo (SOUZA, 2010).

\subsubsection{Histórico e contexto atual do Programa}

Primeiramente foi entrevistado o Gerente atual (E1), quem informou e descreveu o cenário atual do Programa no Estado de Sergipe. De acordo com o entrevistado, o estado de Sergipe possui um total de 90 mil clientes ativos, gerando uma carteira de empréstimos de 
aproximadamente $\mathrm{R} \$ 16$ milhões de reais. O valor médio de contratação por cliente é por volta de R\$ 500 reais e a inadimplência não chega a $2 \%$ do valor total da carteira. O público alvo são pequenos empreendedores que se organizam em grupos de ajuda mutua e que necessitam de pequenas quantias para o desenvolvimento de seu negócio.

A maior parte, cerca de 80,5 \% são empreendedores informais ou em processo de formalização. 17,5\% são micro empreendedores individuais (MEIs) e menos de 2\% são microempresas. Os clientes informais são orientados pelos agentes de crédito e parceiros como o SEBRAE sobre a importância e benefícios para a formalização. As microempresas geralmente são clientes antigos que, devido ao relacionamento, pagamento em dias e realidade do negócio vão renovando novos créditos e se beneficiando do programa enquanto seu negócio cresce e toma um novo formato.

A equipe é formada por 1 diretor coorporativo, funcionário do BNB, 1 gerente geral, 15 agentes de crédito e 6 profissionais de atendimento naagência. Os recursos são aplicados pelo banco e subsidiados por programas de linha de crédito federais. É operacionalizado pelo INEC (Instituto Nordeste de Cidadania), sendo um instituto terceirizado pelo BNB. Possuem parcerias com órgãos como a Fundat e o SEBRAE que operacionalizam capacitações e consultorias para o desenvolvimento dos membros dos grupos financiados. A taxa de juros é bem abaixo do mercado, com atendimento in loco personalizado e adaptado à realidade do empreendedor. A própria dinâmica do programa visa favorecer a rede de cooperação entre empreendedores.

\begin{abstract}
"Ao longo do atendimento in loco dos agentes de crédito, foi possível adaptar a metodologia do aval solidário para a realidade dos empreendedores. Treinamentos e repasse para a equipe são constantes. A metodologia do aval solidário já é avaliada hoje como uma forma de contribuir para que o programa venha oferecer crédito àquelas pessoas de baixa renda". (E1)
\end{abstract}

\title{
4.1.2 Histórico e contexto da implantação do programa em Sergipe
}

A segunda entrevistada foi a gerente que implantou o programa em Sergipe (E2). Tal implantação foi parte do projeto piloto iniciado em 1997 em 5 estados do Brasil. A implantação foi baseada no exemplo sul-americano do Banco Sol, na cidade de La Paz na Bolívia, que foi pioneiro na utilização do aval solidário no microcrédito. Muitos treinamentos, visitas e reuniões foram necessárias para que o projeto piloto fosse montado e aplicado à realidade brasileira.

"Passei meses interna no Banco Sol, analisando e aprendendo a metodologia que teríamos que aplicar no Brasil. Visitas e reuniões de alinhamento com a Matriz em Fortaleza foram bastante importantes para concretizar de forma mais homogênea o funcionamento do programa no Brasil". (E2) 
O projeto piloto veio com o desafio de adaptar para a realidade brasileira o sucesso alcançado em agências sul-americanas. Houve certo receio por parte da equipe quanto à viabilidade do programa, devido à cultura de inadimplência dos brasileiros. Receio que foi logo superado nos primeiros anos de funcionamento, pois foi constatado um baixo índice baixo de inadimplência, se comparada a outras linhas de crédito convencionais. De acordo com a entrevistada, tal situação está diretamente relacionada ao aval solidário, à cooperação entre os empreendedores e o acompanhamento do agente de crédito.

"A principio não acreditava muito na ideia devido à cultura de inadimplência do brasileiro e pela proposta de livrar o cliente de garantias reais. Via que a cultura Boliviana, com os clientes do Banco Sol, era bastante distinta, já que todos faziam questão de pagar as contas em dias e a inadimplência lá era próxima de zero, inclusive em algumas aagências era sim de fato zero". (E2)

A operacionalização do projeto piloto foi simultânea com outras 4 agências no Nordeste e foi sendo adaptada à realidade de cada regional e repassada as melhorias para aplicação do programa nas demais agências. Uma das adaptações verificadas foi com o objetivo de reduzir custos e operacionalizar as visitas in loco dos agentes de crédito. No inicio, no projeto piloto, toda a equipe do Crediamigo era formada por funcionários do banco, o que aumentava os custos do programa e dificultava a rotina de visitas aos empreendedores. A iniciativa para contornar essa realidade foi a terceirização da equipe e agentes de crédito, sendo que no inicio foram contratados estagiários dos cursos de Administração e Ciências Contábeis para a atuação como agentes de crédito. Após o projeto piloto, visando reduzir custos e garantir a qualidade e periodicidade dos acompanhamentos, foi feita a parceria com a terceirização do INEC para a operacionalização do programa.

\subsubsection{Prática do programa pelo ponto de vista dos agentes e clientes}

Por último, foi entrevistado simultaneamente um agente de crédito (E3) e um empreendedor cliente do programa (E4). Verificou-se a plena satisfação do cliente quanto ao funcionamento do programa. A cooperação entre os grupos é incentivada pelo agente de crédito que promove reuniões e capacitações favorecendo a rede.

"É um trabalho muito bem feito, porque uma pessoa está acompanhando a outra, então, você tem essa responsabilidade de fazer um bom trabalho. Se uma pessoa ruim entrar, ela vai colocar todos os outros em risco". (E4)

O agente de crédito descreveu sua rotina de trabalho que consiste em visitar clientes e acompanhar o desenvolvimento do grupo. Os agentes de crédito têm observado, nos grupos consolidados já há algum tempo, uma melhora no relacionamento entre os integrantes, aumentando a parceria e confiança entre eles consolidando o grupo como uma rede de cooperação.

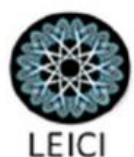


"Todos aqueles que procuram o Crediamigo já tem a consciência da formação do grupo, e o fato de ter que formar um grupo é algo aceitável, apesar de, ainda, para alguns seja um primeiro impasse para o empréstimo". (E3)

\subsection{A SICRED}

$\mathrm{O}$ segundo caso analisado refere-se à modalidade de cooperativismo financeiro praticado em uma cooperativa de crédito. Para esse propósito, foi escolhida a SICRED Sergipe, com o objetivo de analisar as particularidades da cooperação entre os cooperados no sistema SICRED de microcrédito. A rede formada pelos empreendedores, profissionais, gerentes e outros agentes vinculados à cooperativa de crédito permitiu considerar a modalidade de cooperativa de crédito uma importante modalidade de cooperativismo financeiro.

A SICRED é uma cooperativa de crédito, uma instituição financeira diferenciada de um banco convencional, mas que oferece os mesmos serviços e atividades. Sua principal característica é a de ser uma instituição sem fins lucrativos, que é formada por uma associação autônoma de pessoas que se unem voluntariamente, para satisfazer aspirações e necessidades econômicas em comum, por meio de um empreendimento coletivo fundamento na solidariedade, independência, autonomia e gestão democrática. Foi fundado em 1998, em principio trabalhando apenas com cooperados médicos da região de Sergipe. Em 2002 abriram a adesão para profissionais e empresas de todos os setores da saúde e, apenas em 2008, abriram para todos os setores da economia, o que possibilitou um crescimento vertiginoso de cerca de $130 \%$ ao ano. Hoje conta com 3226 cooperados, com depósitos totais de R \$ 79 milhões, possuindo um capital social de quase 30 milhões. Vale ressaltar que todo o resultado é distribuído entre os cooperados, sendo assim, os resultados até hoje são favoráveis para o crescimento da rede, visto que alcançaram um valor de mais de $\mathrm{R} \$ 10$ milhões em 2014 e, desde sua fundação, e já distribuíram mais de 34 milhões de recursos entre seus associados.

Com relação aos empréstimos, conta com uma carteira de 90 milhões de recursos emprestados, demonstrando um crescimento de $300 \%$ (qual o período?quais anos? Entre X e $\mathrm{Y}$ anos). Tal crescimento demandou uma equipe maior e a oferta de produtos de microcrédito orientado mais adaptado à realidade dos empreendedores cooperados.

\subsubsection{Contexto do atendimento empresarial dos cooperados, produtos e serviços}

De acordo com o gerente de negócios (E5), os maiores diferenciais de uma cooperativa de crédito frente a uma instituição financeira convencional é que as sobras das cooperativas são distribuídas aos cooperados e o atendimento é realmente personalizado de acordo com a necessidade de cada membro.

"Na SICRED o cooperado é de fato o dono da instituição. Sendo assim ele é atendido de forma personalizada visando o atendimento de suas necessidades financeiras, possibilitando uma parceira na 
aplicação de seus recursos e concedendo o microcrédito de acordo com suas reais particularidades." (E5)

A gestão da cooperativa visa promover um ambiente de cooperação entre seus cooperados, buscando a máxima rentabilidade e crescimento econômico para todos. Toda a gestão é orientada pelos sete princípios cooperativistas que caracterizam essa modalidade de cooperativismo financeiro: 1) A adesão livre e voluntária, seguindo a resolução do Bacen; 2) a gestão democrática, com a participação democrática dos cooperados na assembleia geral que define o repasse dos rendimentos e a eleição do conselho administrativo e fiscal. Esse princípio define que cada cooperado tem poder de voto igual, independente do numero de cotas ou valores investidos na cooperativa. 3) Participação econômica dos cooperados, com a garantia de retorno financeiro pela aplicação, com critérios definidos de retiradas e rendimentos, bem como os recursos disponíveis para empréstimos. 4) Autonomia e independência, que se refere a autonomia local da SICRED/SE frente às outras agencias do sistema; 5) Educação, formação e informação, com a destinação de $10 \%$ do resultado para o FATES (Fundo de Assistência Técnica, Educacional e Social) com objetivo de apoiar a educação, capacitação e informação técnico-cientifica de seus cooperados. No caso são oferecidos recursos para capacitação e conhecimento cientifico dos cooperados. 6) Inter cooperação, com a filosofia de cooperação entre os membros cooperados, através da formação de rede de cooperação e ajuda mutua. 7) Interesse pela comunidade, com o objetivo de reverter ganhos para o sociedade e desenvolvimento local.

\subsubsection{Contexto dos empréstimos e microcrédito no sistema de cooperativas de crédito}

Foram entrevistados, simultaneamente o gerente de relacionamento (E6) e um empreendedor cooperado usuário do microcrédito fornecido pela SICRED (E7). O gerente ressaltou que, diferente das linhas de crédito convencionais, a fonte de recurso do microcrédito na SICRED são os próprios cooperados, portanto é necessário trabalhar com critérios bastante rígidos na concessão desses recursos, uma vez que a própria missão da cooperativa é assegurar retorno financeiro a todos os cooperados. Sendo assim, uma dificuldade encontrada na concessão de empréstimos, principalmente no microcrédito, é a formalização dos empreendedores e a dificuldade de obter garantias reais.

"Temos muita dificuldade de concretizar o microcrédito, visto que muitos empreendedores não são formalizados e os que são, poucos possuem garantias reais, para que possamos destinar os recursos de seus colegas cooperados para seu empreendimento" (E6).

Apesar dessa dificuldade, as taxas de juros, burocracia e acompanhamento dos empréstimos são grandes diferenciais.

"Por ser uma cooperativa de crédito, é possível destinar recursos com uma taxa incrivelmente mais baixa do que o mercado convencional. $\mathrm{O}$ atendimento e $\mathrm{o}$ acompanhamento são 
personalizados, quase zerando a burocracia, possibilitando uma melhor orientação e resultado na aplicação dos recursos". (E6)

Assim a satisfação sobre o microcrédito, bem como seus resultados são bastante positivos e exemplares. A inadimplência atual está em menos $2 \%$ e o desenvolvimento dos empreendedores acontece de forma natural, sem muitas dificuldades devido à cooperação estabelecida com outros cooperados e a gestão da cooperativa. Tal como afirma o empreendedor cooperado, sobre a utilização do microcrédito da cooperativa:

"O próprio atendimento personalizado e os valores da cooperativa favorece a cooperação Posso contar com as sobras anuais da cooperativa, ao mesmo tempo em que tenho à minha disposição um crédito que me permite aproveitar oportunidades momentâneas."

A seguir o Quadro 5 sumariza as principais características das duas instituições analisadas:

Quadro 5-Características das Instituições estudadas

\begin{tabular}{|c|c|}
\hline CREDIAMIGO (Aval Solidário) & SICRED (Cooperativa de Crédito) \\
\hline Maior Programa de Microcrédito no Brasil & É uma cooperativa de Crédito \\
\hline Orientado pelo Banco do Nordeste & Diferente de um Banco Convencional \\
\hline 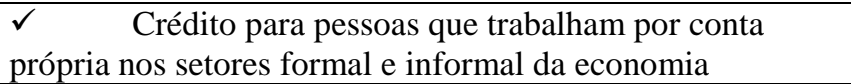 & Instituição sem fins lucrativos \\
\hline $\begin{array}{l}\checkmark \quad \text { Presente em mais de } 2000 \text { municípios do Nordeste, } \\
\text { Minas Gerais e Espirito Santo. }\end{array}$ & $\begin{array}{l}\checkmark \\
\text { Formada por uma associação autônoma } \\
\text { de pessoas }\end{array}$ \\
\hline$\checkmark \quad$ Valor médio de Contratação: $\mathrm{R} \$ 500, \mathrm{oo}$ & $\checkmark \quad$ Atua em todos os setores da economia \\
\hline $\begin{array}{l}\checkmark \\
\text { carteira }\end{array}$ & $\begin{array}{l}\checkmark \quad \text { Conta com } 3.226 \text { cooperados e detém } \\
\text { um capital social de R } \$ 30 \text { milhões }\end{array}$ \\
\hline $\begin{array}{ll}\checkmark & \text { Formado por: } 80,5 \% \text { de empreendedores informais } \\
\checkmark & 17,5 \% \text { de MEIs e } 2 \% \text { Microempresas } \\
\end{array}$ & $\begin{array}{l}\checkmark \quad \text { Os resultados são divididos entre todos } \\
\text { os cooperados }\end{array}$ \\
\hline $\begin{array}{l}\checkmark \quad \text { Orientadores: Agentes de Crédito e Parceiros } \\
(\text { Sebrae })\end{array}$ & $\begin{array}{l}\checkmark \quad \text { Obteve um crescimento de } 300 \% \text { nos } \\
\text { últimos cinco anos }\end{array}$ \\
\hline
\end{tabular}

Fonte: Pesquisa de Campo (2017)

\section{Considerações Finais}

O presente estudo apresentou e analisou duas modalidades distintas de cooperativismo financeiro. Analisou a prática do microcrédito cooperativo nessas modalidades como fator de desenvolvimento e oportunidade para as MPEs. Buscou-se entender nessas modalidades o funcionamento da rede de cooperação que possibilita ganhos além dos recursos financeiros concedidos. Entende-se que o cooperativismo financeiro é muito além de apenas facilitação ao acesso ao crédito, ou mesmo uma alternativa não-convencional de fonte de empréstimos.

No que se refere aos resultados dos casos, as modalidades se apresentam como uma excelente oportunidade para o desenvolvimento das MPEs, em especial pelo microcrédito, aos MEIs (Microempreendedores Individuais). O cooperativismo financeiro, tal como colocado por Anthony (2005), além de possibilitar o acesso ao crédito de empreendedores com 
dificuldade nos meios convencionais, permite o estreitamento de laços de confiança e cooperação que os ajudam no desenvolvimento de seu negócio. De forma complementar, Magdalon e Funchal (2016), afirmam que o microcrédito está inserido no contexto das microfinanças, e que também se estabelece como um fator analítico sobre o desenvolvimento das MPEs, em particular para os MEIs e para empreendedores informais.

Como limitação da pesquisa, pode-se destacar que poucos estudos da temática de micro finanças costumam relacionar o cooperativismo financeiro ao microcrédito e ao desenvolvimento das MPEs. Grande parte dos estudos nessa temática abordam a gestão financeira e obtenção e aplicação de financiamentos pelas MPEs. Da mesma forma, destacase para sugestões de futuras pesquisas, o aprofundamento da análise das modalidades aqui destacadas e também a análise de outras modalidades de cooperativismo financeiro, seja relacionada ou não ao microcrédito como fator de desenvolvimento.

\section{REFERENCIAS:}

ALICE, L.; RUPPENTHAL, J. E. Microcrédito como fomento ao empreendedorismo na base da pirâmide social. Gestão da Produção, Operações e Sistemas, Ano 7, nº 1, p. 23-34. 2012.

ANTHONY, D.. Cooperation in microcredit borrowing groups: Identity, sanctions, and reciprocity in the production of collective goods. American Sociological Review, n. 70, v.3, p. 496-515. 2005

ALLISON, T.H.; DAVIS, B.C.; SHORT, J.C.; WEBB, J.W.. Crowdfunding in a prosocial microlending environment: Examining the role of intrinsic versus extrinsic cues. Entrepreneurship Theory and Practice, v. 39, n. 1, p. 53-73, 2015

BARONE, F. M.; LIMA, P. F.; DANTAS, V.; REZENDE, V. Introdução ao microcrédito. Brasília: Conselho da Comunidade Solidária, 2002.

CHOLAKOVA, M.; CLARYSSE, B. Does the Possibility to Make Equity Investments in Crowdfunding Projects Crowd Out Reward-Based Investments?. Entrepreneurship Theory and Practice, v. 39, n.1, p. 145-172. 2015.

GALERANI, J. . Formação, estruturação e implementação de aliança estratégica entre empresas cooperativas. RAE Eletrônica (Online) , v. 2, p. 1-16, 2003.

GERIZ, S. D. As cooperativas de crédito no arcabouço institucional do sistema financeiro nacional. Prima Facie-Direito, História e Política, v. 4, n.1, p. 82-110. 2004

KHAVUL, S. Microfinance: Creating opportunities for the poor? Academy of Management Perspectives, v. 24, n. 3, p. 57-71. 2010

KHAVUL, S.; CHAVEZ, H.; BRUTON, G. When institutional change outruns the change agent: The contested terrain of entrepreneurial microfinance for those in poverty. Journal of Business Venturing, v. 28, n. 1, p. 30-50, 2013.

MAGDALON, W. P.; FUNCHAL, B. O efeito do Microcrédito Produtivo Orientado No Brasil: Incentivo A Inadimplência? BASE - Revista de Administração e Contabilidade da Unisinos, v. 13 , n. 3 p. 294-308. 2016 
MATIAS, A. B.; QUAGLIO, G. M.; LIMA, J. P. R.; MAGNANI, V. M. Bancos versus cooperativas de crédito: um estudo dos índices de eficiência e receita da prestação de serviços entre 2002 e 2012. RAM, Rev. Adm. Mackenzie, v. 15, n. 5, p. 195-223, Oct. 2014.

MEINEN, Ê.; PORT, M. Cooperativismo de Crédito - Percurso Histórico, Perspectivas e Desafios. Brasília, 2014.

MENEZES, C. R. OURO FILHO, A. SANTANA, J. R. Como o microcrédito contribui para o desenvolvimento das mpes? Estudo multicasos em empresas participantes do apl de confecção de sergipe. RPCA - Revista Pensamente Conteporaneo em Administração. v. 7, n. 3, p. 81-97, 2013

NEUMAN, L. W. Social Research Methods: Qualitative and Quantitative Approaches. Needham Heights, MA: Allyn \& Bacon. 1997

NERI, Marcelo (Org.). Microcrédito, o mistério nordestino e o Grameen brasileiro: perfil e performance dos beneficiários do Crediamigo. Rio de Janeiro: FGV, 2008.

ORDANINI, A.; MICELI, L.; PIZZETTI, M.; PARASURAMAN, A. Crowd-funding: Transforming customers into investors through innovative service platforms. Journal of Service Management, v. 22, n. 1, p. 443-470. 2011

RIGHETTI, C. C. B. Efeitos do microcrédito na geração de renda em microempreendimentos: avaliação de impacto do programa Real Microcrédito. Tese (Doutorado) - Fundação Getulio Vargas. Escola de Administração de Empresas de São Paulo, São Paulo, 2008.

SANTOS, C. A. dos. Cooperativa de crédito. Série empreendimentos coletivos. p. 45. Brasília: Sebrae. 2009

SAUNDERS, M. N. K.; LEWIS, P.; THORNHILL, A. Research methods for business students. England: Pearson Education, 2000.

SEBRAE. O que é o Microcrédito. Brasília: Sebrae. 2014.

SHANE, S. A. General theory of entrepreneurship: the individual-opportunity nexus. North Hanpton: Edward Elgar, 2003.

SOUZA, M. C. G. F. de. O desenho do Programa Crediamigo do Banco do Nordeste: inclusão social e mercado. Fortaleza: BNB, 2010.

WHEELOCK, D. C.; WILSON, P. W. The evolution of cost-productivity and efficiency among US credit unions. Journal of Banking \& Finance, v. 37, n.1, p. 75-88, 2013.

YIN, R. K. Applications of case study research. 2. ed. Thousand Oaks: Sage Publications, 2003.

YUNUS, M. O banqueiro dos pobres: a revolução do microcrédito que ajudou os pobres. $1^{\text {a }}$ ed. São Paulo: Ática, 2000.

ZOUAIN, D. M.; BARONE, F. M. Excertos sobre política pública de acesso ao crédito como ferramenta de combate à pobreza e inclusão social: o microcrédito na era FHC. Revista de Adm. Pública, v. 41, nº 2, 2007. 